\title{
Dríginal Dapers.
}

\section{GONGENITAL AUDITORY IMPERGEPTION (GONGENITAL WORD-DEAFNESS) : WITH REPORT OF A GASE.*}

\author{
By C. WORSTER-DROUGHT and I. M. ALLEN, London.
}

\section{INTRODUGTION.}

CASES of ' word-deafness' that can be regarded as congenital are of considerable rarity. Owing to the disorganisation of speech-mechanisms that inevitably results from this auditory defect and which constitutes the most striking clinical feature, many such cases in the past have been misinterpreted and described in terms of the speech disorder or of a supposed mental defect, without any indication of the impairment in the field of auditory perception. There has, indeed, been no general agreement among writers as to the most suitable term to apply to the condition.

In the case described the outstanding defect is the inability to appreciate the significance of spoken words ; but, in addition, there is also considerable inability to distinguish between less specialised sounds. It would appear that the term 'word-deafness' is too limited in scope to apply to this case, while the same may be said of the terms ' word-sound-deafness' and 'word-meaningdeafness.' On the other hand, the term ' congenital auditory agnosia' has too broad a significance, as implying a total lack of ability to differentiate between any sounds whatever. The term 'congenital auditory imperception' is free from these objections and probably describes the fundamental defect more completely. The only difficulty in the use of this term is that 'word-deafness' has been sanctioned by usage in adult cases and will probably on this account continue to be used in congenital cases. The application of 'congenital worddeafness' to these cases is only justifiable as long as it is remembered that more than the mere auditory appreciation of words is defective, that the defect in perception may extend to other less specialised sounds, and that the term is used in a general sense only.

\footnotetext{
* From the West End Hospital for Diseases of the Nervous System, London.
} 
The present communication is confined solely to a description of the clinical features of a case of congenital auditory imperception based upon routine methods of examination, together with a discussion on the nature of the primary defect present. It is hoped in later communications to deal with the results of more specialised methods of examination; also, to review and discuss the subject, especially the exact relationship of so-called congenital word-deafness to speech defects such as 'idioglossia.'

\section{PERSONAL GASE.}

T.T., male, age 12 years, was brought to hospital on March 24, 1928, for investigation because his speech had always been imperfect.

History of present condition.-He was a full-term child ; instruments were used at the confinement but there was no definite evidence of injury to the child during birth; the mother had much vomiting during labour and died 12 hours after the confinement. Up to the age of 13 months the boy was in the charge of his grandmother and after that of his mother's sister, who then became his stepmother.

He was always a very healthy child and rather forward in many ways. He invariably had a peculiar cry-low and moaning-quite unlike that of other children of his age. He sat up at four months; cut his first tooth about ten months; walked at ten months, and could run at eleven months. He did not, however, attempt to say words at the usual time. His grandmother tried to teach him to talk by getting him to repeat sounds and words after her; he could do this at ten months but never made any attempt to say words of his own accord ; consequently, by the time he went back to his own home at 13 months he had never said anything spontaneously.

In infancy he took notice of all that went on about him at the usual time. From the age of three months onwards it was observed that if he was spoken to he took no notice. At four months, when he was able to sit up in his perambulator, he never took any interest in, or smiled in response to, people who spoke to him but pushed them aside to see horses and vehicles go by. His interest in things he could see was always unusually acute.

At 14 months he would make a noise to indicate to his stepmother that he wanted her to do something or to attract her attention. At two years he learned to say " Cocka-doodle-doo"; he was probably induced to do so on each occasion by shouting it in his ear. About three years he would say his name, but only after someone had said it in his hearing. At three years he had a fall on the left side of the head; following this he had a discharge of a watery fluid and a little blood from the left ear but it rapidly cleared up. At three years he had shown no evidence of association between sounds and objects, when suddenly it was noticed that hè went to the door if he heard his father coming. After this he continued to look for his father if he heard a sound at the door. About this time, he learned to say his prayers by repeating them word for word after his stepmother; but he never at any time attempted to say them himself. He was always amused and laughed when he attempted to say the word "simplicity."

Before the age of five years he was sent to a Deaf and Dumb School at Margate, where he remained six months, and was taught to repeat the names of a few objects. He was taken away because he was surrounded by children who did not talk and his parents thought that he would be better in the company of children who could talk. He was able to say "Mummy" and "Daddy" before going to this school, and after he returned he was able to say " run" and "jump."

At three years and again at five years he had an operation for the removal of adenoids. He then went to a day-school and picked up some words from other boys. At nine years he called boys "Jack" and "Jim"-the appropriate names; he also called his parents 
"fools" when they did not please him, at which they were delighted, as the expression was used in the right sense and as it seemed on an appropriate occasion. He stayed at school until six months ago.

The following history was obtained from the stepmother, a very intelligent woman. The boy did not understand what was spoken to him. He was taught to say some words by a teacher who was a friend of the family. The teacher would get him to watch her, say such a sentence as " Take an apple off a dish and eat it," and then carry out the action herself. After constant repetition he understood if he watched what the command meant and would carry it out himself.

He could read words like " dog," "cat," " hen," " pig," " bat," " there," " this," "Mummy" and "Daddy." He could also associate the word read with the animal or object ; e.g., if he saw the word " $\mathrm{dog}$ " he would point to the animal if one were near. He was taught to read at the Deaf and Dumb school, and can read simple and elementary words, but does not like doing so. If a word is said in his hearing, " his mind appears to get hold of the one idea" and he repeats the word constantly. He has not been tried often with printed or written words.

He can now speak spontaneously; he talks a great deal at times and is readily understood by those who are accustomed to him. Sometimes he cannot be understood at all. He mispronounces words ; e.g., he says " note" for "coat"; his parents are in the habit of withholding the coat until he pronounces the word properly; after several attempts he gives the correct pronunciation. His stepmother is not certain whether he knows that he makes the mistake. He mixes words with signs and gestures and so expresses himself. He can speak a whole sentence such as "Mummy's gone out " quite normally, but it is rarely that he does anything as well as this. He has some "speech" and definite "words" now, but it is uncertain if there is any grammatical sequence. In speaking, he produces a number of sounds, some of them words readily understood, and other sounds which mean nothing to those who are listening to him. He can repeat :-

" Three blind mice,

See how they run,

They all run after__,"

and that is as far as ever he gets. He can sing "doh," " re," " me," "fa" ; his stepmother says he does it correctly only if someone does it with him. He cannot sing a song or air. If someone strikes a series of notes on the piano, e.g., a few syncopated notes and then a run, in his hearing and out of his sight, he can at once reproduce the same general idea-syncopation followed by a run but not necessarily the same notes. He can name some objects, but only those with which he is acquainted and whose names have been taught him ; e.g., he called primroses "flowers." He has said the days of the week in order and correctly, but he does not seem to finish off the words properly. If told that he is wrong in the pronunciation of the word (it is doubtful if this is not where he can see the expression and movements associated with the remark), he at once replies: "It does not matter." He can name "Daddy" and "Mummy." Until the last two years, if he wanted "Daddy" and his mother came first, he would call her "Daddy" ; and the same mistake was made if the positions were reversed.

He writes very well and is fond of writing down his own name, "Mummy," and "Daddy," but sometimes makes errors in writing and transposes letters. He wrote "JCAK" for "JACK," and "GGG" for " EGG." In the latter case, he knew that " GGG" was wrong when he read it, and changed it to "GEG." On being shown that the "E" came first he wrote "EGG." He has also written " HISH" for " FISH." He can sign his name, and prints and writes long hand.

He can read aloud a series of short words, e.g., "The cat sat on the mat." He reads to himself, but will read aloud if made to do so ; usually, he is persuaded to do so by 
showing him a penny. It is not possible to get him to read by telling him to do so, though it would be quite evident that he heard. He may understand a simple sentence such as the above when he is accustomed to it, but not more difficult ones. His stepmother says : "He does not appreciate words." It is not known whether he can understand printed or written commands.

He can copy printed words and printed letters. It is not known whether he can write to dictation; it is probable that he cannot do so. When a direction to do something was written on a blackboard, he did not carry out the command but simply wrote down word for word and letter for letter the command itself.

If a word is spoken in his hearing he can and will repeat it. He always likes to see the movements of the lips of those who are speaking to him. When words are spoken to him in the dark, he can repeat them. He hears the wind and is afraid to go to bed on account of it. He cannot actually tell the time, but he knows " school time," "dinner time," and "bed time."

If a number of objects are placed before him, he can pick out one if its name is spoken but only if he is acquainted with the name and the object as a result of teaching (? by lip-reading). He would not be able to pick out the object if its name were spoken where he could not see the movements of the lips; and he might not understand it if it were printed or written. He can understand gestures and imitate them. If anyone does anything strange, he is apt to imitate him if he sees him doing it. He can pick out objects in a picture and tell about the picture "in his own way." He can convey to those who are used to him an idea of what the objects mean. He can draw from memory. When asked by signs and gestures to draw what he had seen during a visit to a natural history museum, he was able to draw a fish and a skeleton. If he knows what is wanted he can draw it from memory.

He is good at playing such games as football, cricket, cards, whist, draughts and pingpong. He can play all card games and is rather good at them. He can do mechanical puzzles and puts together a Meccano set, takes it to pieces and puts it up again.

Previous Health.-There is no history of any illness before he cut his teeth. At eight months old he fell out of a high chair. At three years old he struck the left side of his head on a stone. At six years he had chickenpox and at ten years whooping-cough.

Family History.-He is the only child; his mother died twelve hours after he was born. His father was 26 and his mother 33 at the time of his birth. There were no miscarriages. His father married his mother's sister thirteen months later; of this marriage there are no children, and there have been no pregnancies. The father is the second in a family of nine, the fourth, fifth and sixth of which died young, one of diphtheria. There is no history of syphilis in the father of this family. The mother was ninth and the stepmother seventh in a family of eleven, the eldest of which died at birth, the second at six years and the eleventh at one month. The third in this family-a female-suffers from "nerve deafness" which began in adult life, while two others-one male and one female-were very slow in learning to speak.

General Condition and Central Nervous System.-He is a bright, intelligent boy and interested in all that goes on about him. His general behaviour is excellent. He plays and enjoys himself with other boys as a normal boy of his age.

The pupils are moderately dilated and react normally; vision is good in both eyes; the visual fields are normal; the optic discs and fundi are normal. No nystagmus. Speech and hearing are dealt with separately. The other cranial nerves are normal.

Sensation is normal. Upper limbs : motor power and tone are normal and equad on the two sides; the tendon reflexes are difficult to elicit, but are equal on the two sides. Lower limbs : motor power and tone are normal and equal; the knee jerks and ankle jerks are present and equal; no ankle clonus ; and both plantar reflexes result in plantar 
flexion. The abdominal reflexes are brisk and equal on the two sides. The gait is normal. There are no spontaneous movements; coordination in the upper limbs is normal; no Rombergism. Sphincters : there is occasional nocturnal enuresis.

All the other systems are normal. The pulse-rate averages 80 ; the blood pressure is 110 systolic and 65 diastolic. The Wassermann reaction in the blood is negative. Skull : there is no abnormality to palpation and X-ray examination reveals no abnormalities.

Examination of the Ears.-Right and left external ears normal. Membrana tympani both sides normal. There is a small white area on the right membrana tympani which might be an old scar. Bone conduction to the tuning fork test is normal in both ears. Air conduction is more prolonged than bone conduction. He can hear low- and high-pitched sounds equally well. Vestibular reactions normal. Rotation tests : rotation to the left results in nystagmus on looking to the right; rotation to the right results in nystagmus on looking to the left.

We are indebted to Sir James Dundas-Grant and Mr. Lionel Colledge for their aural reports.

Investigation of Speech, etc.- - He does not understand what is said to him. When asked, "What is your name ?" from a position in which he cannot see the face or the lips moving, he turns in the direction of the voice but makes no attempt whatever to reply to the question. Commands such as, "Give me your hand," "Open your mouth," "Shut your eyes," from the same position result only in a turning of the head in the direction of the sound. When from a position in which he can see the face and the lips moving, he is asked, "What is your name ?" he replies correctly at once, "Tommy Toft." Subsequently, asking him his name and directing him to perform certain actions with the above commands result in his making a series of sounds which have no resemblance to words or syllables. The sounding of a tuning-fork close to his ear without his seeing it results in his saying a word which resembles "tong." Directions to write his name, or to name the days of the week from a position in which he cannot see the examiner produce no result beyond the turning of the head in the direction of the voice.

2. When shown printed instructions-e.g., "Shut your eyes," "What is your name ?" -he reads the command slowly from beginning to end, looks inquiringly about him, but makes no attempt to carry out the command.

3. Spontaneous speech : He is reported to have said spontaneously "I can bath myself this morning." His voice is low, thin, toneless and monotonous ; there is no distinction or variation of tone in the syllables; the first part of a word is pronounced fairly well but the end of it fades away into a thin whine. He sometimes produces four or five words in order, but as a rule he rarely says more than two words at a time. He is obviously not aware of errors in what he says or in his pronunciation of words; having said his name or read a command aloud, he looks at one as if he expected appreciation of what he has said, and shows no anxiety if he has mispronounced, clipped or mistaken a word. As a rule, his 'speech' is confined to single words. He produces 'speech' and 'words' in the manner described above. The rare sentences he uses are grammatical, though the problems contained therein are perfectly simple. When an attempt is made to convey anything to him by lip-reading or by showing him a printed command, he sometimes responds with a jargon which has no resemblance to the formation of words or syllables. After seeing one say a word, he may repeat it four or five times. When shown "Three blind mice" on a paper, he repeats "Three blind mice, see how they run" and stops there; the words are sufficiently formed to indicate that he is repeating these words, but the last four could not be understood if one did not know that he was attempting to say them. Meanwhile he makes an obvious attempt to see what is printed on the paper. 
4. He can name objects, though often on account of his monotonous and asyllabic voice it is difficult to understand what he says. He calls a mirror, "mirror"; a book, " book"; a fountain pen, "pencil"; and a pin "pin." Occasionally, he does not use the accepted word or name for an object, but employs a sound used constantly whenever that object is pointed out. When asked (by lip-reading) to say the days of the week in order, he utters a series of sounds which fade off but can be recognised as attempts at saying the names of the days in order. The beginning of each word can be recognised as the consonantal sound of S, M, T for Sunday, Monday, Tuesday; but the rest of the word fades into a whining sound. In his expression of the word "Saturday," the " $S$ " and the differentiation into three syllables can be distinguished. When asked to say the names of the months, he produces a series of sounds of one, two or three syllables which cannot be recognised as the names of the months; occasionally, there is one which bears some resemblance to the accepted pronunciation, e.g., "January." He counts quite well from 1 to 30 , but from "sixteen" onwards the " $t$ " sound of each word is replaced by an " $\mathrm{k}$ " sound. When asked, "Who is at home ?" he repeats the question word for word, pauses for a long time, and then says, "Daddy," "Mummy," and " dog "-followed by a series of sounds which apparently represent words but cannot be understood as such. "Daddy" is expressed as a " $d$ " sound followed by a sound trailing off, in which two syllables can be distinguished.

5. When asked (by seeing one speak) "Write your name," the results vary. When the materials are not quite prepared for him, he waits until they are arranged, stares about him and makes no attempt to carry out the instructions. When the question is repeated and everything is ready, he writes "WHEN." On again being told, "Write your name ; your name," he writes "MAN." When "your name" is repeated, he writes "TO MAN." When "Your name ; Tommy Toft" is spoken, he writes "TOMMY TOFT."

6. He can read aloud from an elementary school book quite well. He reads "Is the cow in the yard ?" slowly and with long pauses between the words. He reads single words which do not form a sentence much better and more quickly. He apparently understands what he reads. When shown the printed words "What is your name ?" he reads the sentence word by word aloud, but apparently does not understand the significance of what he has read and makes no attempt to reply. He has not been persuaded to repeat the substance of what he has read. In a picture he names "cow," "tree," "pig" and "cloud" when they are pointed out.

7. He can copy written and printed letters and words. When "CAT" is shown to him he prints "CAT" correctly. He does sums in arithmetic involving addition, subtraction and multiplication, and writes correctly the various stages in the different processes.

8.: He cannot write to dictation when the speaker is out of his sight. When he can see the lips and face moving and " TOMMY TOFT" is dictated to him, he writes " TOMMY TOFT" correctly.

9. He repeats simple words, e.g., " dog," " cat," when spoken to him both from where he cannot and from where he can see. He also repeats a short sentence : "It is Monday."

10. He recognises and names the hours of a watch and can tell the time. When shown a watch and asked "What is the time ?" he answers correctly, "twenty to six." $\mathrm{He}$ does not set the hands of a watch correctly. When asked to set the hands at "four o'clock," he first sets them at " a quarter to six" and then at "ten past six."

11. He cannot pick out objects named when the name is spoken out of his sight. For a "pencil " he picks up a penny ; for a " pen," a sixpence ; and for a "penny," a florin. When the name is spoken where he can see the speaker, he picks out correctly a pen, a pencil, a sixpence, and a penny. When the names " penny," "sixpence," and "pencil" 
are printed, he reads the name aloud and picks out each object correctly. He cannot pick out colours when the name is spoken out of his sight, but he does so correctly when he hears one speak.

12. He understands gestures quite well and imitates them.

13. He plays simple pieces on the piano. He plays simple pieces from the manuscript and makes some mistakes but does not show that he is in any way disturbed by discords. He plays a simple piece that he has often played before, both with his eyes open and with them covered. He makes mistakes, and again is not disturbed by discords. When a series of musical notes are sung out of his sight, he repeats the phrases used but does not sing the notes correctly. He is not in any way disturbed by his mistakes.

14. He hears and recognises the sound of a tuning-fork and indicates by signs that he knows what it is. Afterwards, an unmusical note made by hitting two pieces of metal together is described by him in signs as a tuning-fork.

15. Playing a card game- "Snap "-which depends upon the prompt recognition of the simultaneous appearance of cards of the same value, he recognises similarities very quickly and long before his opponent.

16. During the Oxford-Cambridge boat race he was persuaded to put on the ear-phones to listen to the account of it by wireless. He kept them on for one to two minutes, then took them off, threw them on the bed and went off to attend to something else. (His stepmother says that at home he is sometimes persuaded to put on ear-phones, but he will never listen for more than a minute or two.)

17. He said spontaneously to the boy next to him: "Have you a coat?"

18. In naming objects pointed out to him one by one, he names some correctly but for others uses a sound which is not recognisable as the name of the object. He has a sound which he employs for the name of such an object each time it is pointed out. In one case, he was directed : "Tuning-fork ; pick it up," the object being pointed out at the same time. On five successive attempts, when it was pointed out and he was directed to name it, he said: "Pick it up" and did not realise his mistake. Finally, after it was named several times before him, he named it correctly : "Tuning-fork."

\section{GLINICAL GOMMENTARY.}

The case is that of a boy of twelve who has had difficulty in learning to speak and, even now, is unable to make himself understood by those who are not accustomed to him. In spite of a somewhat difficult confinement, he showed no evidence of injury at birth and now exhibits no features which can definitely be ascribed to intracranial injury. He has developed normally, both physically and mentally, and on physical examination reveals no abnormalities other than the speech defect and the associated phenomena. As an infant, he used his limbs in the normal manner and as a boy indulged in the usual physical activities of a boy of his age. He showed early in life that he suffered from no defect of hearing or of the muscles of articulation, for it was observed by his grandmother, in whose care he was, that he could hear words and sounds and would attempt to repeat them after her.

Thus it was soon evident that there were no defects in the peripheral organs of hearing and sight, and still less in the muscles of articulation and expression. These observations are confirmed in every particular by the results of physical examination. As time went on, it was evident to his parents that he was normal in every way except for his speech defect; so much so, that at the age 
of five they were unwilling that he should remain at a school for the deaf and dumb " because he was not really deaf," and were able to sum up his disability in the words : "He does not appreciate words."

Since it was thus early apparent that his defect was in the field of reception, it is necessary to examine the evidence upon which this observation was based and to consider in the first place the deficiency associated with the reception and interpretation of sound.

During the first three months of his life it was noticed by his grandmother, who was experienced in the ways of infants, that he always had a peculiar, low and moaning cry quite unlike that of other children of his age, in spite of the fact that he was a perfectly healthy child and unusually advanced in other ways. In other words, he continued to use the monotonous, toneless cry of his first utterance induced at his birth as a pure reflex act from the assumption of the function of respiration and adjustment to environment, and he did not learn, as most infants of his age, to express the affective states of discomfort, pain, hunger and pleasure by different cries and sounds. At the age of four months, he failed to respond to variations in sound or speech in the usual way-a distinctly abnormal feature in a child of that age. Kahlmann ${ }^{1}$ indicates that the average infant of three months should react to sudden sounds and to variations in sounds, and includes a test based upon this fact in his series of mental tests for infants of that age. Up to the age of three years there was no evidence of spontaneous speech, and none of memory for sounds and their association with objects, persons and affective states. Such words as he had said before that age were in the nature of parrot-like repetitions, and were induced in every case by constant repetition of particular words in his hearing. It is true that at the age of fourteen months he made a "peculiar sound" vi Jraw the attention of his stepmother to him, but there was in this nothing in the nature of word- or even of syllable-formation. At the age of three he apparently associated a certain sound with the arrival of his father, but it is by no means certain that he did not associate his stepmother's expression with the event. At the age of five he was at a Deaf and Dumb school for a short period and from that age the clinical picture, in consequence, is complicated by the practice of lip-reading and the association of movements of the lips and changes in the facial expression with persons, objects and affective states. It is sufficiently clear, however, that from earliest infancy the child did not appreciate the nature and significance of sounds, and that his disability was not due in any way to impairment of hearing.

It was obvious at an early age that if there was any defect in the field of visual reception it was of a comparatively minor type. The boy took notice of all that went on about him at the usual time, and at the age of four months showed definite evidence not only of memory for visual impressions, but also of a decided preference for visual impressions as compared with auditory impressions. His interest in things he could see was always unusually acute, 
and he recognised horses and vehicles easily at an early age. He also knew his father, stepmother and grandmother when he saw them. It is apparent, therefore, that there was no failure to recognise pictures even in infancy, though, as will be seen later, with the progress of his education certain minor defects in his memory for visual impressions were revealed.

The evidence arising from the history of the boy after he learned to lip-read is most conveniently considered together with the results of the detailed investigation of his receptive aphasia. From these it is evident that he never had anymemory for word-sounds and that that for auditory impressions was also deficient. He simply repeated words as he heard them, and often repeated them many times but with no obvious appreciation of their meaning. There is no response whatever when he is told to repeat the words of a rhyme with which he is acquainted; but he can repeat eleven words of it after he sees the examiner repeat the first three words a number of times. He does not understand at all what is said to him ; questions and commands spoken out of his sight result in no response other than a turning of the head in the direction of the voice, an attempt to see the lips of the person speaking, or a parrot-like repetition of the first word or two of the sentence. He cannot write from dictation when the speaker is out of his sight. He cannot pick out objects named when the name is spoken out of his sight, and invariably mistakes the object when, by other methods, he is made to understand what is required of him. He does not recognise mistakes in music ; is not disturbed by discords ; and fails to repeat correctly a number of musical notes sung in his hearing. He does not appreciate or even understand descriptions heard by listening in on a wireless set, but will listen to organ music with evident appreciation. He has, however, a certain memory for sounds of an uncomplicated nature; he has an obvious sense of fear when he hears the noise of the wind at night, and he can recognise the sound of a tuning-fork though, in the latter case, he fails to recognise that a decidedly unmusical noise is different. Since physical examination shows that both middle and internal ears are perfectly normal, it is evident from the above that there is a complete absence of memory for words and musical tones. Because of the absence of this elemental feature essential to the normal development of speech, he failed to use words spontaneously and in their correct associations until he acquired the art of lip-reading at the age of five. Hence, while fully recognising the futility of endeavouring to place the different parts of the speech-mechanism in separate and clearly defined " centres " and accepting the complete interdependence of each speechelement, it is desirable, for the sake of simplicity in discussion, to use the term of the older nomenclature-centre-without implying the existence of a definite anatomical centre.

With an entire absence of a "word-memory centre," it is evident that, with the perfection of lip-reading, the boy would have to build up from his memories of lip movements and facial expressions and their association with 
persons, objects and affective states, a new "centre" for the memory of words which, for convenience in description, we propose to call the "lip-reading wordmemory centre." That the habitual association of various impressions has resulted in a memory for words appreciated by lip-reading is evident from the history and examination of the patient; and that it is as yet imperfectly developed and requires further development is obvious from certain defects and errors which will be referred to later. At the age of four the boy was able to say "Mummy" and "Daddy" to his parents, but was unable to associate the words with the correct individuals if they appeared to him in the wrong order. It was only after he had received instruction for a short time in the practice of lip-reading that he was able to acquire normal words for himself. Hence it is reasonable to suppose that he has developed his present "conventional" vocabulary by seeing and not by hearing others speak. As a rule, he answers questions, obeys commands, and appreciates affective states when he can see the movements of the speaker's lips and the expression of his face. He can name objects correctly when they are pointed out to him and he can understand directions by lip-reading. He can repeat the names of the days of the week and count from 1 to 30 when asked to do so in the same way. He can answer simple questions involving the use of only one word when directed to do so. He can pick out objects correctly when they are named where he can see the speaker. His success in these tests is certainly due to the fact that by habitual association he has built up a memory for words from seeing others speak. He is not, however, always so successful. At times, he does not respond at all, and at others he replies with a series of sounds which have no resemblance to words as others know them. His occasional failure to respond to commands is probably due to the imperfect development of his " lip-reading word-memory centre" ; while his use of jargon and strange sounds, his mispronunciation of numerals above 16 and his use of an unusual sound constantly for a definite object are probably expressions of so-called "idioglossia," a feature of his case which will be referred to at a later stage.

It is now generally recognised that all parts of the speech-mechanism function as a complex whole ; and it is obvious, therefore, that when one part is entirely absent or defective and that which is being produced to replace it is imperfectly developed, the remaining parts will exhibit defects which will vary with the training of the subject. In the patient under discussion, there is an entire absence of the " auditory word-memory centre," and an imperfectly developed "lip-reading word-memory centre." Hence it is only to be expected that some word-blindness and agraphia will be present in addition to the speech defect; and this is what is found.

In spite of the fact that visual memory was apparently perfect in early childhood, the confusion of objects and symbols as the patient's education proceeded revealed some defects in his memory for visual impressions. That they are only minor defects is shown by the fact that he remembers faces, 
recognises objects in pictures, recognises similarities and differences in playingcards more readily than other boys of his age, reads and answers written questions, reads and obeys printed commands, draws sketches of what he has seen from memory, recognises concrete objects and animals, reads music and does elementary sums in arithmetic. That there are definite defects present is shown by his occasional difficulty in appreciating and carrying out simple printed commands, by his failure to recognise a mistake in the spelling of simple words with which he is well acquainted, and by his response to the written command "Write your name." Slight defects in writing are revealed in his persistent transposition of letters in the printing of simple words, though his failure to recognise and correct the mistake may have been due in part to his defect in visual word memory. The association paths between hearing and speaking are apparently normal, since he is able to repeat words parrotlike as they are spoken to him. There is also a certain lack of appreciation of the exact nature of the sounds he hears, as he occasionally repeats the words imperfectly and at times fails to repeat musical notes correctly though at other times he can do so. As far as can be determined from observation, all his other associations are normal provided that no stress is placed upon his " auditory word-memory centre," and as long as the stress placed upon his "visual word-memory centre" is not too great. There remains, for consideration, however, the speech defect and its effect upon the development of the intelligence and usefulness of the individual.

In learning to speak, the normal infant at first becomes preoccupied with the sounds he is producing as a result of certain affective states; he practises them constantly and from time to time adds new sounds to his vocabulary and so brings them to perfection, partly with the help of his imitation of the sounds made by his elders in his hearing and partly by his own appreciation of the sounds he himself utters during his constant repetitions. Later, he associates definite sounds made by himself and others with certain objects and persons seen, felt, smelt, tasted and heard ; and, finally, knowing that he is capable of making sounds of different kinds he attempts to imitate his mother when he hears her use definite sounds in connection with definite objects. In this way he learns to speak. The patient under discussion revealed a defect in his speech mechanism in early infancy in the form of his cry, which was constantly the same and did not vary with the affective state giving rise to it. He made no attempt at all to practise sounds himself and at the age of 13 months had never said anything spontaneously. At the age of 14 months he made some attempt to develop a spontaneous language in the "strange sound" he made to attract the attention of others to him, but this sound did not resemble anything he had heard or the words others had tried to teach him. At the age of five his whole vocabulary consisted of the parrot-like repetition of " Cock-adoodle-doo," his own name, "Mummy" and "Daddy." It is apparent, therefore, that up to this age he had relied entirely upon the repetition of sounds as he 
heard them for his language. Then a new factor-the influence of his knowledge of lip-reading - was introduced into the development of his language. Henceforth, he had three factors upon which to rely :-(1) his association of lip movements and facial expressions with objects, persons and affective states ; (2) his repetition of sounds as he heard them in association with objects, concrete and abstract, without any appreciation of their finer variations ; and (3) his imitation of the gestures of others in his attempts to express his meaning. It is evident that, to a child handicapped as he was and with only a very elementary education in lip-reading, these methods of expression would probably appeal in the inverse order to that in which they are mentioned above. Gestures he has always relied upon freely to express his meaning, and even now he uses them intelligently whenever he finds that he cannot make himself understood by other means. The influence of the other two factors will be readily understood from his subsequent history and from his present condition. He soon learned to use definite words, sometimes with startling appropriateness ; he has gradually developed a small vocabulary of normal words, and does at times, though rarely, use short sentences spontaneously. This is the limited extent to which he has developed his knowledge of "conventional language," probably entirely as a result of his education in lip-reading. He relies, chiefly, however, upon a series of expressions of his own. At times, asking him questions and directing him to perform certain actions result in his making a series of sounds which appear to have no resemblance to words or syllables ; but subsequent investigation of this apparent "jargon," word by word, reveals in it a structure which is constant for the sounds applied to definite objects. Minor degrees of this variation are apparent in his saying "note" for "coat" and in his replacement of " $t$ " by " $k$ " in the names of numerals over 16 .

\section{AN INDIVIDUAL LANGUAGE: IDIOGLOSSIA.}

It is obvious, therefore, that he has developed a language of his own based partly upon his attempt to reproduce sounds exactly as he has heard others produce them, and partly upon his observation of the movements of lips and other structures by others when they are uttering words. That the latter is at least a minor factor in the production of his language is supported by the fact that when he meets a word with which he is apparently unfamiliar, he attempts to imitate step by step the movements and expression of the speaker before he actually produces his version of the word as a whole. His low, thin, monotonous voice and his apparent asyllabic sounds show, however, that he has built up a great deal of his language from constant imitation of the sounds produced by others but without any appreciation of their finer variations. This "individual " language of his, therefore, is almost certainly of the nature of "idioglossia." That it is true "individual" language and not a mere " jargon" is supported by three observations : (1) by constant observation its structure and meaning can be appreciated ; $(2)$ those in constant contact 
with him can understand easily what he means in spite of the queer sounds he produces; and (3) other children understand readily what he means even at the time of their earliest association with him.

That there is a definite "idioglossia" of the type described by Bastian, ${ }^{2}$ Guthrie, ${ }^{3}$ and $\mathrm{McCready}^{4}$ is supported by the following examples of his language. The letters of the alphabet are consistently named by him in order : "aiee, bee, hos, aiee, bee, eff, tea, gee, aiee, fum, to, orl, yem, ko, oo, pee, ker, puf, ess and ets, tum, uu, vets, wee or weet, dumu, whale, wez"; the numerals from 1 to 30 are named: "wun, tu, tumee, fuore, fief, tiksch, teven, aitt, nocee, teee, lefer, twefee, doka, fuukee, fifikee, tuku, tiviku, aaku, numku, twerku, wikawun, wikatrue, wikatume, wikafuor, wikafife, wikakik, wikakeven, wika-aak, wikanee, tukee"; the tens are called: "teee, twerku, tukee, fuokee, fifikee, tikee, kiwikee, atkee, nikee"; one hundred is called "agu-agu"; and one thousand "agu-oo." Examples of the names used for common objects are: "tikipu " for sixpence ; " tu kwivee kik" for two and sixpence; " kepu" for spoon; " toto" for tie ; "nops" for nose ; "peku" for pen ; "pickapok" for pocket ; and " toof" for coat. It is interesting to note that when these words of his "individual " language are used as he says them, he fails to understand their meaning; but recognises quite readily the corresponding "conventional" words when they are used in their place. The naming of the letters of the alphabet agrees in some respects with that in six cases of "idioglossia " mentioned by Guthries, including those of Hale-White and Golding Bird ${ }^{5}$, Taylor ${ }^{6}$, and Hadden ${ }^{7}$; but in many cases the terms employed are peculiar to the individual. The exact relationship of "idioglossia" to congenital auditory imperception, we hope to discuss in a further communication.

The subject of this communication is at least of average intelligence, which confirms the opinion expressed by $\mathrm{McCready}^{4}$ that a high degree of congenital "aphasia" is not incompatible with normal or even superior intelligence. Bronner $^{8}$ has pointed out that, in such cases, a definite relationship may exist between the "aphasia," abnormal behaviour, and unusual emotional reactions. In our patient the emotional reactions are perfectly normal and his behaviour is all that could be desired, probably because there is in him and his family no inherent tendency to emotional instability. Regarding the psychological reactions to the disability mentioned by Orton $^{\circ}$, there is no suggestion of any thing that might lead to asocial behaviour, an observation which is of some importance in view of the reputed association of the handicap with delinquency in children. On the whole, the boy shows a contented, apathetic disregard of the handicap and its results ; he is perfectly happy in his life as it is ; but when the prospect of earning a living in adult life is forced upon his attention, he exhibits a slight sense of inferiority in his reply that he will never be able to do so as he cannot speak. This sense of inferiority is, however, of a very slight degree and not sufficiently prominent to affect his behaviour and his relationships with his teachers and his fellows. 


\section{ETIOLOGY.}

It is interesting to speculate upon the pathological cause of the condition in the patient described. There are two possible primary factors to be considered, viz., (1) the effect of a birth injury in the production of an intracranial hæmorrhage with consequent damage to structures in the temporal lobes of importance in the development of the speech mechanism ; (2) the presence of a biological variation comparable with colour-blindness. It is difficult after twelve years to decide if a minor intracranial injury has been present or not; but at least this case exhibits no physical or mental abnormalities which could be ascribed to injury at birth. It is true that there was every chance that some such injury might have occurred, for the confinement was unusually severe, instruments were used, and the mother died twelve hours later. The various minor injuries to the head which the boy suffered from the age of eight months onward, and the development of adenoids, can, we consider, be ruled out as factors in the production of the condition simply on the knowledge that definite speech defects were present many months before. The determination of a possible biological variation or stigma of degeneration as the important factor is more difficult. It is true that at present a tendency exists to ascribe "spastic diplegia" (Little's disease) and other conditions of the same type to cerebral aplasia rather than to the effects of intracranial hæmorrhage at birth, but in the consideration of a particular case all possible factors must be carefully considered before any conclusion, can be reached. The strongest and only argument in favour of a biological variation in the present case is the fact that the defect is of a familial character. There is no defect whatever on the father's side or in his family; but there is definite evidence of difficulty in learning to speak in members of the mother's family. The mother of the subject was perfectly normal in her acquisition of speech, but in her family of eleven brothers and sisters there were three others in whom there was difficulty in learning to speak or in the appreciation of sounds. One sister of the mother, now the subject's step-mother, spoke first at the age of four and not at all distinctly until she was ten, although she was able to read easily long before she was that age ; another sister is reputed to suffer from " nerve deafness"; while a brother was a little backward in speaking and at the age of three could not pronounce most of his words well enough to be understood. Careful investigation of the previous generation on both the grandfather's and grandmother's side fails to reveal any defect of speech or " hearing." Thus there is definite evidence of the presence of a familial factor in the etiology of the condition, an influence also noted in cases of "congenital word blindness " by Thomas ${ }^{10}$, Fisher ${ }^{11}$, Stephenson ${ }^{12}$, Hinshelwood ${ }^{13}$, Plate ${ }^{14}$, McCready $^{4}$, and in idioglossia by Hadden ${ }^{7}$, Hale-White ${ }^{5}$, and Taylor ${ }^{6}$. In our patient, like that of Stephenson's, the defect is apparently transmitted through a healthy female to her male offspring, though in the latter case it was noted that the transmission from a previous generation was through an affected female. 
Whether the familial defect is of the nature of a simple biological variation or of a local aplasia affecting those parts of the brain concerned with the reception and association of sounds it is difficult to determine. A secondary factorloss of the stimulation and encouragement of the child's own mother-may have played some part in the perpetuation of the defect, but it could not have had any influence upon the actual production of the defect. Other children in a like situation do not show defects in the appreciation of sound and in the development of speech, though it is true that if exposed to an environment in which stimulation and encouragement are absent, they may not progress as rapidly as other children. The influence of adenoids, from which the subject suffered and for which he had two operations, can be excluded as an important factor, for, as Guthrie points out, in spite of the fact that they may produce defective utterance they cannot alone account for idioglossia. Hence it may be concluded that in this case the balance of evidence is in favour of the influence of a biological variation of unknown nature and origin as the important factor in the causation of the defect. The influence of birth injury cannot, however, be absolutely excluded.

\section{SUMMARY.}

1. A case is described which is regarded as one of " congenital auditory imperception" ; complete word-deafness, or more strictly, word-meaningdeafness, is the most important element, but there is some degree of auditory agnosia. Slight word-blindness, slight agraphia or dysgraphia, and a pronounced speech defect are associated secondary elements.

2. The disorganisation of the speech-mechanism has led to the development, in the patient concerned, of a method of expression which is of the nature of so-called "idioglossia" -an "individual language" representing an extreme form of mispronounced and ill-expressed conventional language.

3. The case illustrates the interdependence of each and every elemental part of the speech-mechanism and especially the dependence of normal speech development upon the appreciation of variations in sounds. The observations carried out tend to confirm the modern view that the speech-mechanism cannot be divided into clearly defined "centres," but must be regarded as a physiological mechanism which functions as a complete whole.

4. As regards the causation of the disorder, the balance of evidence is in favour of a biological variation or of local aplasia, but birth injury cannot be definitely excluded.

5. The case raises important questions such as the influence of congenital " word-deafness " upon the development of speech defects such as "idioglossia," the influence of such a defect upon the development of general intelligence, the psychological reactions involved in those affected with such disability, their influence on behaviour and delinquency, and the importance of applying special methods of education to such cases in order to enable the individual to attain a self-supporting economic position and to prevent the development of antisocial tendencies. 


\section{REFERENCES.}

1 Kahlmann, F., Handbook of Mental Tests, Baltimore, 1922.

2 Bastian, H. C., Aphasia and other Speech Defects, London, 1898.

${ }^{3}$ GUTHris, L., Functional Nervous Disorders in Childhood, London, 1907.

4 McCready, E., Amer. Jour. Psychiat., 1926-27, vi, 267.

${ }^{5}$ Hale White, W., and Golding-BiRd, C. H., Trans. Med-Chir. Soc., 1891, lxxiv, 181.

6 TAYLOR, F., ibid., p. 191.

? HADDEN, J., Jour. Ment. Sci., 1891, xxxvii, 96.

8 Bronner, A., The Psychology of Special Abilities and Disabilities, Boston, 1919.

9 ORton, S. J., quoted by McCready (Ref. 4).

10 Thomas, C. J., Ophthalmoscope, 1905, iii, 380.

11 Fisher, J. H., Ophthalmic Review, 1905, xxiv, 315.

12 Stephenson, S., Ophthalmoscope, 1907, v, 482.

13 Hinshel wood, J., Brit. Med. Jour., 1907, ii, 1229.

14 Plate, E., Münch. med. Woch., 1909, 1793. 